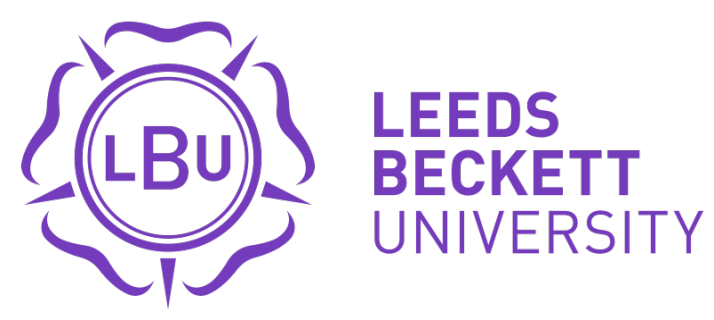

Citation:

Topic, M (2018) Not Bloke-ified enough? Women Journalists, Supermarket Industry and the Debate on Sugar in the British Press (2010-2015). Newspaper Research Journal, 39 (4). pp. 433-442. ISSN 0739-5329 DOI: https://doi.org/10.1177/0739532918806872

Link to Leeds Beckett Repository record:

https://eprints.leedsbeckett.ac.uk/id/eprint/4414/

Document Version:

Article (Accepted Version)

The aim of the Leeds Beckett Repository is to provide open access to our research, as required by funder policies and permitted by publishers and copyright law.

The Leeds Beckett repository holds a wide range of publications, each of which has been checked for copyright and the relevant embargo period has been applied by the Research Services team.

We operate on a standard take-down policy. If you are the author or publisher of an output and you would like it removed from the repository, please contact us and we will investigate on a case-by-case basis.

Each thesis in the repository has been cleared where necessary by the author for third party copyright. If you would like a thesis to be removed from the repository or believe there is an issue with copyright, please contact us on openaccess@leedsbeckett.ac.uk and we will investigate on a case-by-case basis. 


\title{
Not Bloke-ified Enough? Women Journalists, Supermarket Industry and the Debate on Sugar in the British Press (2010-2015) ${ }^{1}$
}

\begin{abstract}
The paper analyses debates on sugar and the supermarket industry in the British national press in a period between 2010 and 2015. The main premise of the paper is that traditionally 'female' subject areas of journalism (health, supermarkets) have migrated from 'soft' news sections to 'hard' news pages of newspapers, and when this happened women journalists were squeezed out of covering these issues; instead, most topics on hard news pages become the preserve of male journalists.
\end{abstract}

Key words: women, journalism, newspapers, national press, UK, conceptual, content analysis, health, sugar debate, supermarket industry, feminisation, blokes

\section{Introduction}

Women journalists have historically faced obstacles in entering journalism profession as well as progressing to editorial positions. When women first started to join journalism, many male reporters were objecting towards this change arguing that women cannot cope with shifts and that they will change the nature of the news. For example, some male journalists stated that women "have class bound voices unsuitable for news reading... (and) may introduce emotion", while the others were saying that women, "would be unable to work in the cold and wet... and (are) not able to make overnight stays on location with a man as wives would not like it" ${ }^{1}$. In addition, one editor stated that women were seen as unable to handle "hard news stories...(but) see themselves as experts on women's features"'.

In the UK, women worked in journalism since $19^{\text {th }}$ century but they started to gain full-time employment in larger numbers only during 1960s, and their numbers remain uneven to men ever since. Nevertheless, even though the number of women in journalism increased and even though women journalists are more educated than their male colleagues, as it will be discussed later in the paper, women remain unable to fully progress in their careers. In other words, it is not only that there are very few female editors, but sections such as business, finance and news remain male dominated areas. Journalism as a whole remains a male dominated profession immersed in the masculine culture of deciding what constitutes news, and available data points towards conclusion that the equality of women in journalism in general (in the UK as well as elsewhere) is still a goal to be achieved ${ }^{3}$.

This paper looked at the position of women in the UK press in regards to sugar debate and the supermarket industry in a period from 2010 until 2015. The reason for selecting this topic is that available data shows it was women who brought health and food in newspaper pages and thus these topics were for a long time considered as soft and 'feminine' news ${ }^{4}$. As available data also shows that health is entering newspaper agenda in the $\mathrm{UK}^{5}$ this paper investigated to what extent women write about these topics now when health and food are no longer present in health and food pages but also in the main news. In addition, the UK's supermarket industry is increasingly becoming involved with sugar debate because media are questioning supermarket's commitments towards helping in reducing obesity and many supermarkets nowadays include health and reducing sugar as part of their corporate social responsibility policies ${ }^{6}$.

\footnotetext{
${ }^{1}$ The author would like to thank two anonymous reviewers for helpful and friendly comments on an earlier draft of this paper, as well as Dr Ioannis Kostopoulos and Dr Audra Diers-Lawson for their advice in revising the paper according to reviewer's instructions.
} 
The main premise of the paper is that traditionally 'female' subject areas of journalism have migrated from 'soft' news sections to 'hard' news pages of newspapers and that when this happened women journalists were squeezed out of covering these issues; instead, most topics on hard news pages become the preserve of male journalists, whatever their origins in the field of journalism. The research takes one such example - health issues, and sugar and supermarkets and the obesity crisis in particular - to see if this is the case for this topic.

\section{Literature Review}

Journalism has been a male industry for centuries even though "what newspapers choose to print is of primary importance in shaping the way we view ourselves, our communities, our country and the world"7. However, even though women have started to gain employment in newspapers during 1960s, the first female editors in the UK were appointed only in 1987 in The News of the World and the Sunday Mirror, both tabloid newspapers. The skills because of which these women were hired were feature expertise ${ }^{8}$.

The Daily Mail introduced lifestyle, fashion, education and health after 1986, and the golden period for women in journalism started in late $1980 \mathrm{~s}^{9}$, as this is the period when women started to work in journalism in higher numbers than ever before. This is not to say that women did not work in journalism before, however, their progress has always been hindered by masculine culture and the expectation that a journalist is to be a male. For example, Rachel Beer was editing the Observer in 1891 and the Sunday Times in 1893 but during the whole $20^{\text {th }}$ century there were almost no female newspaper editors of UK broadsheet papers ${ }^{10}$.

Early research conducted by Graber ${ }^{11}$ showed that women have merged in the male newsroom culture. In other words, news values and information gathering techniques remain unchanged even though the number of women in the industry has increased, and Graber's findings have been confirmed in later research ${ }^{12}$. It has also been argued that the journalistic culture is so masculinised that women who stay in journalism and progress to senior position "become so bloke-ified by the macho water in which they swim that many younger women looking up don't see them as role models for the kind of women they might want to become"13. Nevertheless, Gallagher ${ }^{14}$ noted that women are not expected to join the somewhat 'laddish' behaviour, and many do not feel comfortable with that culture anyway.

It has been a long-standing view that even though women are more educated than men and $13 \%$ of women were more likely to be Oxford or Cambridge graduates compared to $2 \%$ among male journalists ${ }^{15}$, journalism remains a male profession ${ }^{16}$. This view has been confirmed in new data according to which there are more male than female journalists and men earn more than women in journalism ${ }^{17}$. In addition, old age starts at 45 for women, as it is more women who are facing redundancies and rejections of freelance collaborations than men who progress to senior positions as they age ${ }^{18}$. Women also seem to be younger than men in terms of how long they have been working in journalism, which corresponds with previously discussed views of journalism as a male profession and the late arrival of women to the industry. For example, one study ${ }^{19}$ looked at length of service in newspaper journalism by women and men, and they found that journalists who worked over 20 years in journalism are predominantly men (46\% of men as opposed to $16 \%$ of women). The situation is not better when it comes to journalism in general and not just newspapers, where $35 \%$ of men and $12 \%$ of women stated they have been working for over 20 years. New data for the UK revealed similar numbers, and $67 \%$ of men are reported to have 30 and more years of work experience as opposed to $33 \%$ of women who reported the same ${ }^{20}$. 
The number of women editors remains low even though available research suggests that women are those who buy newspapers more and thus female editors could be able to find ways to appeal to women to save declining circulations. ${ }^{21}$ Nevertheless, some authors argue that women have changed the content of newspapers by adding topics that used to be considered trivial and less important, such as "women's health, children and child-care, family matters, education and health" 22 . This also means that women have contributed towards making a difference in expanding the definition of news and areas of news since women journalists introduced topics that are of interest to women. Craft and $\mathrm{Wanta}^{23}$ found that newspapers with female editors contributed towards diversity in coverage as those newspapers focused not just on negative aspects of the news but also positive ones. This finding corresponds with negative views expressed by certain editors as explained at the beginning of the paper, according to which women cannot handle hard news, however, the fact women brought some positivity can also be interpreted as if women brought diversity in the news coverage. According to the same research, it appears that women are more inclined to threat staff equally. Thus, in newspapers where women are editors both male and female reporters had a chance to cover similar issues whereas in male-dominated newsrooms male reporters were predominantly covering politics, often considered as a "prestigious beat" 24 .

When it comes to health, according to available data, women tend to be interested in this area more than men, and women were generally reported to be interested in "different subjects from men: medical and health news; letters; food and recipes; clothes and fashion; horoscopes; royal news and social gossip", and both men and women were equally interested in "domestic news, and personal and family money matters" 25 . However, health news has a priority for women as opposed to men who are mostly interested in sport ${ }^{26}$. Some authors ${ }^{27}$ also argued that "the "masculine" journalism focuses on politics, crime, finance, education and upbringing, while "feminine" journalism involves human interest, consumer news, culture and social policy".

Regardless of whether women readers are interested in different issues than men and that female journalists have brought different topics into the newspaper coverage that interest women, has also brought to the situation that women do not work in business sections of newspapers as much as men. According to research conducted by Bawdon ${ }^{28}$, majority of frontpage stories and by-lines in the national newspapers in the UK were written by men. In other words, $78 \%$ of all by-lines were written by males and $22 \%$ were written by females. Bawdon's research has also revealed that women do not act as lead writer of the main story often ${ }^{29}$. For example, in 2011, "in a typical month, $78 \%$ of newspaper articles are written by men, $72 \%$ of Question Time contributors are men and $84 \%$ of reporters and guests on Radio 4s Today show are men" 30 (Cochrane, 2011, online publication). According to the research of by-lines in UK's national newspapers conducted by Women in Journalism organisation, in 2011, "there wasn't a single day, on a single newspaper, when the number of female by-lines outstripped or equalled the number of male by-lines". ${ }^{31}$

Historically it was women who brought health and social affairs into the news, changes in approaching stories to add a human touch to writing, and also explaining how stories and news are relevant for the readers. As such, news is placed in a more specific context since women joined the field, inevitably brining change to the content of news pages as well as change of the news agenda because health stories have started to appear more in the newspapers than before $^{32}$. These changes also lead to the minimization of the old divisions of hard and soft news(i.e. at first topics on health and education were considered as soft news but as health and education entered the agenda and became part of politics, this division started to disappear ${ }^{33}$ ). When it comes to 'soft' news and 'female' areas, then women were seen as thriving, for example, life style and 'pink ghettos' found that women were thriving as authors - even over- 
represented ${ }^{34}$. Yet, this also corresponded with a perception that women were not able to handle hard news ${ }^{35}$. Some authors also noted that with the increased prioritisation of the so-called soft news in the media, women gained increased status in newsrooms ${ }^{36}$. This paper therefore examined this assumption in more details by looking into the position of women journalists who write on anti-sugar debate and the supermarket industry in the UK press. ${ }^{37}$

\section{Method}

In this study, articles for the analysis were selected from LexisNexis database for a period between 15 December 2010 until 15 December 2015 and a content analysis has been used as a method for the analysis. Due to large number of articles published on sugar and the supermarket industry in the UK in the period of five years, the analysis focused on narrowing down the search to articles that mention both sugar and the supermarket industry. The keywords used were "sugar" and "supermarket".

The search was firstly performed using the term sugar and then selecting an option 'and', which added supermarket keyword to narrow down the search on articles that talk about both sugar and the supermarket industry. The sub-search consisted of marking all industries, all subjects, all countries, and all UK newspapers. Duplicate options were set to off, and the date was narrowed down to five years (15 December 2010 until 15 December 2015). The search produced 1000 articles sorted by relevance, which were all pre-analysed for suitability for this research.

All 1000 articles have been read, and in total 454 articles have been initially selected for the analysis. The criteria for inclusion of articles in the analysis were that every article discusses sugar and the supermarket industry. Articles that discuss only sugar and/or obesity without mentioning the supermarket industry have been removed from the sample, as well as articles that only write about the supermarket industry in general (e.g. profit, problems, in few instances construction work near certain supermarket, articles on BBC's show The Apprentice where one of the candidates competing for Lord Sugar's investment worked in the supermarket industry before, etc.).

Both national and regional articles have been selected for the analysis to capture differences between regional and national media. The analysis of regional media proved to be impossible as majority of articles do not have an author at all, and thus it was impossible to analyse differences between women and men. Therefore, the first figure in the presentation of results give information on all articles showing an increased interest of the media for sugar and supermarkets, whereas subsequent tables analyse only national media where majority of articles do have an author and articles from regional media have been excluded from the further analysis.

The analysis encompasses counting by-lines, and analysis of sections in which women and men write about the sugar debate. The total amount of articles published in the national media and used for the analysis is 184 . When researching by-lines, journalists have also been googled to establish gender of the writer as it was not always clear who the author is. When there was no photo available on the newspaper website, journalists have been searched on social media until a photo has been found.

The research questions for the study were set as follows, 
a) To what extent women journalists cover topics on sugar and supermarkets in national newspapers?

b) To what extent women journalists cover these issues now when they are entering an agenda and can no longer be seen as soft news?

c) Did entrance of the soft news to hard news in the British press improved the position of female journalists?

\section{Results and Discussion}

According to the analysis of published articles in a period between 2010 and 2015 it is visible that the interest of newspapers in the sugar debate and the supermarket industry is on the rise, and that these issues are entering the newspaper agenda (figure 1).

\section{FIGURE 1 HERE}

In other words, majority of articles on sugar and the supermarket industry in the national and regional press has been published in news section (39.86\%) and $2.42 \%$ of articles on the front page (table 1). The number of articles is on the rise in both national and regional press, however, as it was not possible to analyse regional press due to the fact that they do not publish name of their authors in majority of cases, in the subsequent part of the article a focus will be on national press only.

\section{TABLE 1 HERE}

In other words, the analysis shows that men still dominate the news section with 62 male bylines on this topic with 39 female by-lines (table 1). In other words, the numbers in table 1 testify that the most important sections of newspapers are still reserved for men. On the other hand, the front-page articles on sugar are written by 11 men as opposed to only three women, whereas business articles are written by four men and no women. However, in traditional women areas such as health and food, women wrote more articles than men. In other words, more women wrote articles on health when these were not published in news. When these findings are juxtaposed against the literature review, it appears as if women are being pushed out from a traditional 'feminine' area when that 'feminine' news is good enough to be part of main (hard) news.

In order to evaluate whether the thematic differences observed are significant, a Chi-square post hoc analysis was performed in order to determine whether there was a significant difference between male and female authors by section of the national newspapers. These findings confirm a significant difference between men and women $\left(X^{2}(2, N=184)=5.20, p\right.$ $<.05$.

When it comes to breakdown of newspapers and a question of who writes on sugar and the supermarket industry, it appears that the best balance can be found in The Guardian, The Sun and The Metro where the number is exactly the same (table 2).

\section{TABLE 2 HERE}

In order to evaluate whether the thematic differences observed are significant, a Chi-square post hoc analysis was performed in order to determine whether there was a significant difference between male and female authors by media outlet for national newspapers. These findings indicate there is no significant difference for male and female authors based on overall media outlet $\left(X^{2}(2, N=184)=1.08, p>.05\right.$. Overall, there are no significant differences; 
however, on an outlet-by-outlet basis there may be differences for example, when comparing The Daily Mail to the The Telegraph there is a meaningful difference between the two.

However, more women wrote in Daily Mirror than men, whereas in all other newspapers there were more men writing on these issues than women. The situation is particularly problematic in The Telegraph where 25 articles have been written by men while only six articles were written by women. In The Daily Mail the gap is narrow with 31 men writing articles on this topic as opposed to 27 women, i.e. a difference of four. In other words, women are doing better in tabloids (The Daily Mirror) and newspapers bordering tabloids (The Daily Mail) than in broadsheets (The Telegraph and The Times). If going back to the literature review, it appears that women historically do better in tabloids than broadsheets and the situation has not changed much since the early days.

\section{Conclusion}

In summary, it seems that health entering the public agenda in the UK press has, to an extent, helped women enter the news for some do manage to write on this topic. For example, in the news section analysed in this study 39 by-lines were female as opposed to 62 male (table 1 ). In this sense, it is possible to agree with North ${ }^{38}$ that women's presence in newsrooms increased when soft news also became hard news. However, when it comes to business women have no presence, while they only have a strong presence in health and food sections of the British press where they outnumber men (table 2). Nevertheless, 11 men had a front page story on sugar and the supermarket industry as opposed to only three women (table 1).

This data signals that old divisions to hard and soft news are changing for health and supermarket industry are now in the news, however, old divisions between men and women are not changing and women are still under-represented in the news, front page and business stories. While one could argue that women are generally under-represented in the newspapers because they joined the profession later, it seems difficult to justify why they are underrepresented in these particular areas that have moved from health pages to the news and front page. The question that comes to mind is whether British female journalists are not bloke-fied enough to deserve place in the news? Or, are women still seen as unable to cover hard news and thus they need to share the workload with male colleagues so that the main newsroom remains a place for blokes?

What certainly does appear is that women historically do better in tabloids and that the socalled feminisation of news has helped them increase numbers and their position in the field, however, broadsheets seem to remain a place for blokes when it comes to news, front page and business. Thus, while one could say that the news is getting feminised for a traditional 'feminine' area entered the news, it is not possible to say that the newsrooms are entirely following that trend. In other words, if the data on who writes the news on supermarkets and health (anti-sugar debate) (in this case more men than women) and who brought health topics into the newspaper coverage (women) is taken into consideration, then it seems as if women are being pushed out from traditionally 'feminine' area now when this area became hard news. Therefore, it seems that inequality is transforming to a new level, i.e. not only that there is no equality of women and men in journalism, but women may be pushed out of their traditional areas now when these areas are becoming hard news.

Asking about equality of women and men in the media represents a relevant question not just because media are seen as a fourth estate and watchdogs of democracy, but also because media have the power to contribute towards creating equal societies. Wilkinson and Pickett stated that equal societies "are better to live in (...) and better for everyone" 39 . Nevertheless, national press 
is often considered as the most prestigious area of journalism ${ }^{40}$ and thus asking a question whether women are equally represented in the national press presents a legitimate question. As argued by Janes ${ }^{41}$, "a good and successful newspaper should reflect the society it's reporting on. If women are not in the fabric of the organisation, you've got a worse product". While this was just one case study research that counted by-lines only, the results did reveal problematic situation and one can indeed ask a question whether British press is active enough in creating a better and equal society.

\section{Notes}

\footnotetext{
${ }^{11}$ Susan Franks, Women and Journalism. (London: I.B. Tauris, 2013), 3.

${ }^{2}$ Franks, Women and Journalism.

${ }^{3}$ Monika Lofgren-Nilsson, "Thinkings" and "doings" of "gender". Journalism Practice 4(1) (2010): 1-16; Sarah
} Lonsdale, "WE AGREED THAT WOMEN WERE A NUISANCE IN THE OFFICE, ANYWAY": The portrayal of women journalists in early twentieth-century British fiction". Journalism Studies 14(4) (2013): 461-475; Yong Z. Volz and Francis L. F. Lee, "What Does It Take for Women Journalists to Gain Professional Recognition? Gender Disparities among Pulitzer Prize Winners, 1917-2010". Journalism: Professional and Legal Questions 90(2) (2013): 248-266; Marie Hardin and Stacie Shain, 'Female Sports Journalists: Are We There Yet? 'No'. Newspaper Research Journal 26(4) (2005): 22-35; Hans C. Schmidt, Women's sports coverage remains largely marginalized. Newspaper Research Journal 37(3) (2016): 275-298; Tracy Everbach and Craig Flournoy, "Women Leave Journalism for Better Pay, Work Conditions". Newspaper Research Journal 28(3) (2007): 52-64; Franks, Women and Journalism.

${ }^{4}$ Linda Christmas, "Women in Journalism: Chaps of both sexes? - Women decision-makers in newspapers: Do they make a difference?" Report for Women in Journalism Organisation (1997). Accessed December 212016. http://womeninjournalism.co.uk/wp-content/uploads/2012/10/Chaps-of-both-Sexes.pdf; Monika Djerf-Pierre, "The Difference Engine". Feminist Media Studies 11(1) (2011): 43-51; Hilly Janes, "I've seen tomorrow - and its female". British Journalism Review 22(2) (2011): 39-45; Ford N. Burkhart and Carol K. Sigelman, "Byline Bias? Effects of Gender on News Article Evaluations". Journalism Quarterly 67(3) (1990): 492-500; Louise North, "The Gender of "soft" and "hard" news. Journalism Studies 17(3) (2016): 356-373.

5 Janes, I've seen tomorrow; Christmas, Chaps of both sexes; see also figure 1 in the results section.

${ }^{6}$ Martina Topić and Brian Jones. "Making Sense of UK Supermarkets' CSR Web Communication ”. Journal of Marketing Communications (forthcoming).

${ }^{7}$ Christmas, Chaps of both sexes, 1.

${ }^{8}$ Christmas, Chaps of both sexes 1 .

${ }^{9}$ Janes, I've seen tomorrow.

${ }^{10}$ Franks, Women and Journalism; Yehuda Coren and Eilat Negev. First Lady of Fleet Street: A Biography of Rachel Beer. (London: IR Books, 2011).

${ }^{11}$ Doris Graber. Crime News and the Public. (New York: Praeger, 1980).

${ }^{12}$ Cited from Christmas, Chaps of both sexes; see also Djerf-Pierre, The Difference Engine and Everbach \& Flournoy, Women leave journalism.

${ }^{13}$ Eleanor Mills, "Why do the best jobs go to men?" British Journalism Review 25(3) (2014): 1-5 (online), 2.

${ }^{14}$ Margaret Gallagher, "Women, Media and Democratic Society: In Pursuit of Rights and Freedoms. United Nations: Division for the Advancement of Women (DAW)”, Expert Group Meeting on 'Participation and access of women to the media, and the impact of media on, and its use as an instrument for the advancement and empowerment of women' (2002). Accessed March 222017.

http://www.un.org/womenwatch/daw/egm/media2002/reports/BP1Gallagher.PDF

${ }^{15}$ Mary Ann Sieghart and Georgina Henry, “The Cheaper Sex: how women lose out in journalism”. Women in Journalism Report (1998). Accessed December 26 2016. http://womeninjournalism.co.uk/wpcontent/uploads/2012/10/CheaperSex.pdf

${ }^{16}$ Franks, Women and Journalism.

${ }^{17}$ Thurman, N.; Cornia, A., \& Kunert, J. et al, Journalists in the UK (2016). Oxford: Reuters Institute for the Study of Journalism; Franks, Women and Journalism.

18 Alexandra Campbell, "The Lady Vanishes". Women in Journalism Organisation Report (n.d). Accessed December 26 2016. http://womeninjournalism.co.uk/the-lady-vanishes-at-45/

${ }^{19}$ Sieghart and Henry, Byline bias.

20 Thurman et al, 2016, p. 10. 
${ }^{21}$ Christmas, Chaps of both sexes; Janes, I've seen tomorrow; Chris Shaw, “A men-only meritocracy”. British Journalism Review, blog entry (2011). Accessed January 25 2017. http://www.bjr.org.uk/blog+february_2011 ; Franks Women and Journalism; Mills, Why do the best...

${ }^{22}$ Christmas, Chaps of both sexes, 3; see also North, The gender of 'soft'.

${ }^{23}$ Stephanie Craft and Wayne Wanta, "Women in the Newsroom: Influences of Female Editors and Reporters on the News Agenda". Journalism and Mass Communication Quarterly 81(1) (2004): 124-138.

${ }^{24}$ Craft and Wanta, Women in the Newsroom, 135.

${ }^{25}$ Christmas, Chaps of both sexes, 2.

${ }^{26}$ Christmas, Chaps of both sexes, 2.

${ }^{27}$ Everbach and Flournoy, Women leave journalism, 53.

${ }^{28}$ Fiona Bawdon, "Seen but not heard: how women make front page news". Report for Women in Journalism Organisation (2012). Accessed December 21 2016. http://womeninjournalism.co.uk/wpcontent/uploads/2012/10/Seen_but_not heard.pdf

${ }^{29}$ Bawdon, Seen but not heard.

${ }^{30}$ Kira Cochrane, 2011. "Why is British public life dominated by men?" Women in Journalism Report. Accessed December 26 2016. http://womeninjournalism.co.uk/why-is-british-public-life-dominated-by-men/

${ }^{31}$ Cochrane, Why is British public life...

${ }^{32}$ Christmas, Chaps of both sexes, 42 ; see findings section in this paper.

${ }^{33}$ Janes, I've seen tomorrow.

34 Anthony Delano, "Women journalists: what's the difference?" Journalism Studies, 4(2) (2003): 273-286; Franks, Women and Journalism.

${ }^{35}$ Franks, Women and Journalism.

${ }^{36}$ Van Zoonen, One of the Girls; North, The gender of 'soft'; Catharine Lumby, "The Dichotomy of Pleasure and Power is Too Simple: Critiques on Contemporary Media Moralism (2000). Accessed July 212017.

http://www.nettime.org/Lists-Archives/nettime-1-0009/msg00008.html

${ }^{38}$ North, The gender of 'soft'.

${ }^{39}$ Cited from Djerf-Pierre, The difference engine, 43.

${ }^{40}$ Franks, Women in Journalism, 20.

${ }^{41}$ Janes, I've seen tomorrow, 42. 